
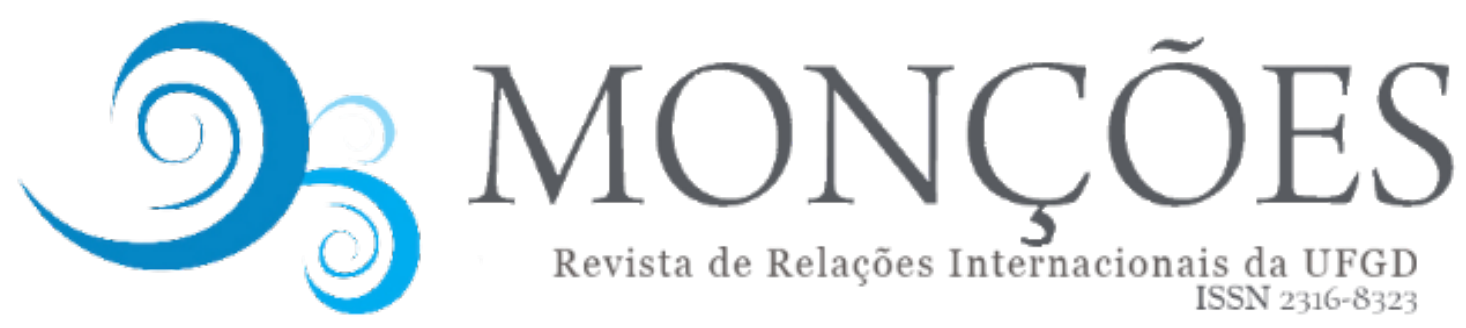

ISSN 2316-8323

A teorização em Relações Internacionais no Brasil importa?

JOÃO NACKLE URT

Professor da Universidade Federal da Grande Dourados (UFGD).

Contato: joaourt@gmail.com

LARA MARTIM RODRIGUES SELIS

Professora do Instituto de Economia e Relações Internacionais da Universidade Federal de Uberlândia (UFU). Contato: laramrselis@gmail.com

VICTOR COUTINHO LAGE Professor do Instituto de Humanidades, Artes e Ciências Professor Milton Santos (IHAC) da Universidade Federal da Bahia (UFBA) e do Programa de Pós-Graduação em Relações Internacionais da UFBA. Coordenador da Área de Concentração em Relações Internacionais do IHAC/UFBA. Vice coordenador da Área Temática de Teoria das Relações Internacionais da Associação Brasileira de Relações Internacionais (ABRI).

Contato: victorclage@gmail.com

\title{
Teoria, Prática
}

Ao longo do processo de formulação desse Dossiê, fomos inúmeras vezes convocados por uma pergunta: "mas, afinal, teoria importa?" Talvez, a você que nos lê, possa soar estranho abrirmos essa publicação interrogando por aquilo que a justifica. Ou ainda, você poderia questionar se, em um contexto de tantos ataques à ciência, em especial às ciências ditas sociais e humanas, seria profícuo problematizar a importância mesma da teorização. No entanto, de mãos dadas a pensadoras(es) como Paulo Freire e bell hooks, aderimos à relevância desse exercício que nasce mais como potência crítica do que dúvida cética. Como um e outra nos ensinam, antes das respostas, é preciso deslocar as estruturas que subscrevem nossas perguntas.

Sob esse horizonte, vale ainda pontuar que não se trata de uma pergunta banal, ainda que bastante comum. Como sabemos, para pesquisadoras(es) da área de Teoria das Relações Internacionais no Brasil, a interrogação sobre a validade de 
seus estudos está bastante presente, explícita ou implicitamente, em grande parte dos diálogos acadêmicos. Por isso, encaramos o engajamento produtivo com a questão "teoria importa?" enquanto tarefa imprescindível nessa introdução. Para tanto, propomos aqui uma reflexão sobre aquilo que habita as entrelinhas dessa indagação, ou seja, suas "condições de possibilidade". Afinal, por que se faz necessário provar o valor da teoria? Quais são, e quem define, os critérios de autorização do conhecimento? Ou ainda, no limite, o que é teoria?

De início, gostaríamos de chamar atenção para a pressuposição de que teoria e prática se opõem. Ao nosso ver, tal conjectura está na base do raciocínio que autoriza as linhas do conhecimento acadêmico. É ela também a responsável pela leitura que insiste em determinar a prioridade de uma dimensão sobre a outra, demarcando uma espécie de identidade essencialista para teoria e para prática. Vale pontuar, contudo, o risco implicado nesse imaginário que opera pela "distinção". Dele, deriva um método de validação dependente da lógica dicotômica ("um ou outro"), cuja estrutura revela-se tragicamente excludente. Portanto, ao que defendemos aqui, um engajamento produtivo com essa questão envolveria, antes de tudo, a problematização da própria dicotomia que encerra a diferença como terreno (ou como alvo) de políticas de identificação. Afinal, é com suporte dessa lógica, que nosso vocabulário acadêmico justifica o valor da teoria e da prática, a depender dos graus em que podemos reconhecer, ou distinguir, uma na/da outra. Para alguns, quanto mais abstrata, mais teórica; para outros, quanto mais material, mais aplicada. Mas afinal, a quem serve essa separação? A quem interessa o essencialismo que dita o que é teoria e o que é prática?

Para responder a tais questões, convocamos mais uma vez a reflexão de hooks, que nos aponta para as estruturas de poder que subscrevem nossos padrões científicos. Na visão dessa autora, a reprodução da "brecha entre a teoria e a prática" tem servido "para perpetuar o elitismo de classe" (HOOKS, 2013, 90). Ou seja, de um lado, tal separação permite que um grupo arrogue para si a prerrogativa da abstração (tomada supostamente como "identidade teórica"). Com isso, uma elite acadêmica perpetuaria as condições de desvalorização dos trabalhos que não se submetam a tais critérios - e que, por isso, são "considerados não teóricos - ou não suficientemente teóricos" (HOOKS, 2013, 88). Por outro lado, a autora também chama atenção para o perigo da própria crítica, elaborada por uma parte dos grupos 
subalternizados, e que opta por um descarte da teoria como campo de disputa, arrogando para si, em antítese, a prerrogativa da materialidade. Eis a fórmula para nossa tragédia binária, em que, às subjetividades hegemônicas, caberia o direito ao abstrato, enquanto que, aos grupos subalternizados, ficaria o dever da reivindicação a um suposto vínculo ao material.

Inevitavelmente, tal polaridade será responsável pelo papel de objeto de estudo impelido aos grupos subalternizados por certos marcadores de discriminação, o que culmina na baixa ou nula presença destes enquanto grupos considerados produtores do conhecimento. Nesse sentido, como anunciamos no início da introdução, gostaríamos de propor a possibilidade de um destino menos trágico aos nossos esforços teórico-práticos ou prático-teóricos. Por isso, nosso convite dispõe o desafio de pensar a diferença como condição de não-identidade. No lugar da lógica da identificação (ou isso/ou aquilo), propomos uma imaginação capaz de supor a impossibilidade mesma do reconhecimento (nem isso, nem aquilo). O fazer teórico, nessa perspectiva, não se edificaria, e tampouco se validaria, por uma essência distinta e/ou oposta à prática. Ambos caminham conectados, autorizando e reconstruindo um ao outro.

Talvez, num movimento de ironia criativa ${ }^{1}$, caminhemos para o desmonte da própria pergunta que balizou nossa reflexão até aqui; afinal, se não há linha rígida nos contornos entre teoria e prática, qual o sentido de questionarmos a relevância de uma ou outra? Talvez, em adição, nossa tarefa seja antes acolher o desafio da própria linha, ou melhor, o desafio de habitar a fronteira. Sob esse horizonte, a proposta deste Dossiê surge do objetivo de recolocar a teoria como parte desse movimento, quer como foco do interesse geral, quer como alvo de um debate público mais amplo. Expandir a teoria (e a teorização) para públicos e territórios diversos significa ampliar também aquelas(es) capazes de acessá-la e/ou produzi-la; ou ainda, reinventar as estruturas capazes de autorizá-la. Uma rede de poder institucional, social, cultural e político é mobilizada quando encaramos e reivindicamos o desafio proposto pela produção de conhecimento. Nossos esforços, enquanto pessoas engajadas nesse campo, devem caminhar para a democratização

\footnotetext{
1 Seguimos, aqui, Oswald de Andrade, para quem a aplicação de estratégias estilísticas, como a ironia ou o paradoxo, pode deslocar as hierarquias da imaginação moderna, em especial, seus binarismos - tal qual, o prático e o abstrato.
} 
dessa teorização - justamente porque nela reside a força transformadora do pensamento.

Dessa forma, nossa motivação responde também à posição marginal que as pesquisas brasileiras assumem dentro da geopolítica que envolve as Relações Internacionais (RI) enquanto disciplina global. Ou seja, uma vez estrangeiros ao norte-global, como ocupar-para-transformar o campo intelectual? Com essa questão, este Dossiê se apresenta como uma oportunidade para refletirmos sobre como o conhecimento em Relações Internacionais, reconhecidamente enviesado pela apropriação intelectual da área pelos Estados Unidos, se apresenta no Brasil, uma chance de indagar se é possível pensar as RI diferentemente e, assim, reivindicar uma produção brasileira de teoria das Relações Internacionais ${ }^{2}$.

Seria possível teorizar em RI no Brasil em diálogo com nomes como Josué de Castro, Darcy Ribeiro, Paulo Freire, Lélia Gonzalez, Florestan Fernandes, Guerreiro Ramos, Abdias do Nascimento, Milton Santos, Sueli Carneiro, Davi Kopenawa, Ailton Krenak, entre tantas outras vozes? Esses diálogos ajudariam a construir uma teoria das RI a partir do Brasil, para além dos esforços já empreendidos no país até o momento? Poderia advir daí uma contribuição do chamado Sul Global às Teorias de RI, ao lado da Teoria da Dependência, que muitos ainda consideram a única teoria proveniente da América Latina a ter importância nas RI?

Que equilíbrio se observa entre os ditames da agenda cosmopolita/global e as origens locais dessas teorias? Podemos as(os) brasileiras(os) falar senão através de uma nova cultura global (Spivak, 2003, p. 618)? Podemos fazer teoria das RI senão através da incorporação de um padrão globalcêntrico (Dirlik, 2005) por certas elites intelectuais, suficientemente educadas nos modos e linguagens da academia forjada no Norte - auto-atribuída a condição de cosmopolita e global?

Além do mais, se, como nos ensinou Cox (1981, p. 128) nos já longínquos anos 1980, toda teoria é feita para alguém e para algum propósito: para quem e para quais propósitos são feitas as teorizações em RI no Brasil? Portanto, quem é esse vago conhecido chamado Brasil? Que espaço-tempo é esse de onde falamos? Que se sabe, que se ensina, que se aprende de Brasil nos cursos de Relações

\footnotetext{
${ }^{2}$ Esse parágrafo se refere à trilogia organizada por Arlene Tickner, Ole Waever e David Blaney e às expressões que esses trabalhos põem em destaque: International Relations Scholarship Around the World (TICKNER; WAEVER, 2009), Thinking International Relations Differently (TICKNER; BLANEY, 2012) e Claiming the International (TICKNER; BLANEY, 2013).
} 
Internacionais no País? Sobre quais opressões, sobre quais cadáveres, sobre quais escombros pisam nossos pés? Ao mesmo tempo, não sendo só de cadáveres esta história, a partir de quais modalidades de resistência e contraconduta, de quais espectros de uma democracia por vir podemos teorizar as RI no Brasil? E que pode isso implicar para o pensamento que se manifesta a partir de nossas subjetividades?

Ao fim, todas essas questões retornam à primeira, que abriu esta seção. Por meio dela, percebemos que afirmar o valor da teoria para o Brasil, desde suas perspectivas plurais, condiz com outra assertiva, talvez mais urgente, e que nos conta sobre o poder da educação como prática de vocalização e nomeação social. Como sugeriu hooks, a produção teórica aponta um território intelectual que precisa ser ocupado, democratizado, reinventado - jamais abandonado. A construção coletiva de ideias exige coragem de fala, aprendizado de escuta e ruptura de silêncios. Nesse sentido, a teorização é espaço de nomeação, onde inclusive a dor pode ser nomeada e escoada (HOOKS, 2013). Quando isso acontece, a fresta entre teoria e prática se refaz, ou se abre diferentemente. Um processo que implicaria, nos termos de Spivak (1999), uma transformação epistemológica profunda, sem a qual uma "ética do encontro" com a diferença não seria possível. Por isso, entendemos este Dossiê como um convite enraizado em seu tempo, o qual ecoa a demanda por valorização do trabalho intelectual, de onde a produção teórica emerge como uma prática social transformadora e aliada aos campos de ensino e extensão, em suas múltiplas direções.

Os textos publicados neste Dossiê trazem à tona considerável diversidade. De partida, nota-se uma ampla variedade na interação de perspectivas teóricas distintas com debates e/ou com conceitos fundamentais - ou mesmo tidos como fundacionais - no campo de Relações Internacionais (RI). Nesse aspecto, o Dossiê traz: os estudos de governamentalidade e sua relação com o conceito de governança global (ver Veloso); a teoria dos papéis (ou role theory) na Análise de Política Externa (APE) (ver Silva e Labriola); a abordagem psicanalítica de Jacques Lacan para o estudo da construção de ameaças no âmbito da segurança internacional (ver Ventura e Pedroso); aportes das teorias gramscianas, feministas, foucaultianas e pós-coloniais para uma interpretação crítica das intervenções humanitárias (ver Borba de Sá); uma leitura pós-colonial do conceito de "estadofalido" (ver Toledo); o debate teórico marxista sobre a "internacionalização do 
Estado" (ver Garcia); o recurso a teorias do imperialismo para o entendimento da hegemonia dos Estados Unidos na ordem internacional contemporânea (ver Mendonça, Cicero e Amaral); a contribuição do feminismo pós-colonial para o estudo da relação entre violência, gênero e refúgio (ver Minvielle); a interpelação que o feminismo não-ocidental traz para o pensamento das/nas fronteiras entre "Oriente" e "Ocidente" (ver Jessica Oliveira); a potencialidade dos estudos pós-coloniais, decoloniais e da sociologia histórica para uma reinterpretação da importância do escravismo atlântico na construção do "internacional" no século XIX (ver Bezerra, Salgado e Yamato); e a problematização de conceitos como "anarquia" e "estado de natureza" a partir do "Sul" (ver Fernández; e Santos Filho).

O Dossiê também contribui para uma reflexão sobre as configurações da própria academia de Relações Internacionais no Brasil. Nessa linha, a teorização nesse campo é discutida com foco, por exemplo, em teses de doutorado apresentadas em certos programas de pós-graduação do país (ver Decol e Silva); ou ainda, por meio de uma comparação de corte geracional entre as configurações acadêmicas brasileira e indiana (ver Muñoz e Spode). Além disso, vale destacar o modo como a produção de conhecimento em RI no Brasil é colocada diante de questões fundamentais de raça e racismo (Jesus; e Ananda Oliveira).

Além dos temas discutidos e perspectivas teóricas mobilizadas em cada texto (aos quais voltaremos abaixo), gostaríamos de apontar dois outros aspectos do Dossiê. O primeiro diz respeito à diversidade do perfil acadêmico das(os) autoras(es), no que se refere à titulação e à experiência profissional. $A(O)$ leitora(leitor) terá acesso a textos de mestrandas(os), doutorandas(os) e professoras(es). No caso das(os) últimas(os), trata-se de nomes em diferentes momentos da carreira profissional, indo de docentes em início de carreira até aquelas(es) já estabelecidas(os) e com vasta produção bibliográfica, além de significativa contribuição - nas múltiplas esferas de ensino, pesquisa, extensão, orientação de graduação e pós-graduação e, o que nem sempre é notado, em tarefas administrativas e institucionais - na construção do campo de RI no Brasil nas últimas décadas. Alguns desses nomes, inclusive, foram professoras(es), em diferentes circunstâncias, da própria equipe organizadora do Dossiê, tornando-o, também nesse sentido, possível. Esse perfil diverso e as muitas pesquisas e 
agendas de pesquisa apresentadas no Dossiê sinalizam a vitalidade da teorização no campo de RI, assim como sua potencialidade para ulteriores desdobramentos.

O segundo aspecto a ser apontado se liga à filiação institucional e à localização regional das(os) autoras(es). O campo de RI se mostra ainda bastante concentrado regionalmente. Mesmo assim, os textos do Dossiê trazem pesquisas e agendas de pesquisa, já concluídas e em curso, conduzidas em quase todas as regiões do país (à exceção, infelizmente, da região norte), em vários estados, tais como Rio Grande do Sul, Santa Catarina, Minas Gerais, Rio de Janeiro, São Paulo, Mato Grosso do Sul, Bahia, além do Distrito Federal. Uma análise mais minuciosa desse segundo aspecto precisaria levar em conta, sem dúvida, não apenas a filiação institucional atual de pesquisadoras(es), mas também sua trajetória de formação. Nesse caso, a concentração se mostraria ainda mais evidente, dado que a diversificação regional dos cursos de pós-graduação no Brasil, em especial dos de $\mathrm{RI}$, é recente. ${ }^{3}$ Ainda assim, parece significativo notar que quase a totalidade das(os) autoras(es) teve sua formação acadêmica majoritariamente no país. Um contraste dessa formação com aquela pela qual passaram gerações anteriores de docentes que atuavam ou ainda atuam no campo de RI muito provavelmente indicaria um crescimento da proporção de titulação em universidades nacionais, assim como da titulação no próprio campo de RI em contraste com campos afins (como Ciência Política, Economia, História, Direito).

A consideração desses dois últimos aspectos do Dossiê não permite, é certo, uma generalização para todo o campo de RI no Brasil. Seriam necessárias pesquisas quantitativas e qualitativas para se verificar a pertinência do que eles parecem indicar. Em adição a isso - e o que nos é mais importante -, não se pode confundir a identificação do fortalecimento desse campo no país com o desejo por

\footnotetext{
${ }^{3}$ Dos 140 cursos de graduação em Relações Internacionais em atividade, 55,7\% estão situados na região Sudeste, $21,4 \%$, na região Sul, $10 \%$ na região Centro-Oeste $(5,7 \%$ apenas no Distrito Federal), $7,8 \%$ no Nordeste e $5 \%$ no Norte. Do ponto de vista do número de vagas, a concentração é ainda maior: $61,6 \%$ no Sudeste, $18,5 \%$ no Sul, $9,3 \%$ no Centro-Oeste, $6 \%$ no Nordeste e $4,6 \%$ no Norte (E-MEC, 2020). O cenário é semelhante nas pós-graduações (PLATAFORMA SUCUPIRA, 2020). Dos 14 cursos identificados especificamente como Programas de Mestrado em Relações Internacionais (ou Ciência Política e Relações Internacionais), 50\% estão sediados na região Sudeste. Dos 8 doutorados, $62,5 \%$ estão no Sudeste. As PUCs e as públicas contribuem para levar a pós-graduação ao Sul e ao Nordeste. No Centro-Oeste, a UnB segue sendo a única a oferecer essa formação. No restante do Centro-Oeste e no Norte, nenhum programa de pós-graduação stricto sensu foi fundado. No Nordeste, neste ano (2020) foi aprovado, em análise de mérito da Coordenação de Aperfeiçoamento de Pessoal de Nível Superior (CAPES), o primeiro doutorado, na Universidade Federal da Bahia, cujo início das atividades aguarda homologação do Ministério da Educação.
} 
especialização e consolidação de fronteiras disciplinares e disciplinarizantes. Aliás, voltando aos textos do Dossiê, parece-nos que boa parte deles vai em outra direção. Se, por um lado, há inestimáveis contribuições para o fortalecimento da teorização no campo de RI no Brasil, o que inclui sua problematização por cortes de raça, classe, gênero e outros marcadores de discriminação; por outro lado, a maioria dos textos contribui para esse fortalecimento através da interação com outros campos do conhecimento, com outras trajetórias de pensamento, inclusive com a produção de conhecimento fora do ambiente acadêmico, explorando ou indicando a potencialidade que reside no atravessamento de fronteiras disciplinares e disciplinarizantes, e não no seu reforço.

Antes de nos aproximarmos do que é discutido por cada texto, gostaríamos de enfatizar algo que vem movendo a iniciativa coletiva que tornou possível o Dossiê. Um dos traços constitutivos da divisão global do trabalho intelectual é a hierarquização entre "centros", concebidos como produtores de teoria, e "periferias", concebidas como consumidoras de teoria e/ou fornecedoras de matéria-prima (material empírico, por exemplo) a ser teorizada nos "centros". Essa hierarquização é amiúde internalizada no próprio ambiente acadêmico "periférico". Uma das implicações disso é a ausência ou a subexploração de debates com o que é produzido nesse ambiente. Não se trata aqui apenas de chamarmos a atenção para a importância da política da citação. Ou melhor, trata-se de defendermos a importância de uma política da citação que não opere na reprodução da lógica produtivista e/ou da mútua garantia de privilégios acadêmicos e profissionais, mas que faça parte de movimentos de contestação dos marcadores de discriminação na produção de conhecimento. Talvez possamos falar em uma política decolonial da citação na produção de conhecimento, que conteste ininterruptamente os termos pelos quais se define quem é capaz de teorizar e a quem se atribui a condição de ser pensante. Não está em jogo nisso a defesa do insulamento acadêmico ou da recusa ao que não é "brasileiro", o que seria o lado oposto da dicotomia que move a importação de teorias ditada pela divisão global do trabalho intelectual. Essa política decolonial requer a problematização dessa dicotomia, o que passa, entre outras coisas, por uma interação crítica com a produção de conhecimento teórico no Brasil. Não por complacência, mas por sua qualidade e por sua inestimável contribuição à teorização de RI no país, como evidenciam os textos deste Dossiê. Vamos a eles. 
Breve panorama dos textos do Dossiê

Vitor Veloso mapeia os muitos usos do conceito de "governança global", largamente mobilizado e influente no campo de RI desde a década de 1990. Identificando nesse conceito uma ineficácia interpretativa, Veloso apresenta o debate, de inspiração foucaultiana e de já longa trajetória em diversos campos de conhecimento (incluindo em RI), promovido pelos estudos de "governamentalidade". Estes, argumenta, propiciam uma "analítica do poder" que problematiza a relação entre soberania, autoridade e legitimidade; ao contrário de desconsiderar, com isso, a importância do estado, o conceito de "governamentalidade" se mostraria mais adequado para a apreensão das transformações das racionalidades de governo que atravessam o estado e outros sujeitos da política.

Irma Oliveira e Silva e Pedro Labriola se dedicam a apresentar a contribuição da teoria dos papéis (role theory) para a Análise da Política Externa (APE). Ligada originalmente à psicologia social, à antropologia e à sociologia, essa teoria propõe que os papeis, entendidos como padrões de comportamento de agentes, se relacionam com estruturas sociais e expectativas de outros agentes no processo de interação. Dialogando com outras abordagens do campo de RI, o artigo argumenta que as especificidades da teoria dos papéis contribuem para o entendimento da relação agente-estrutura e, mais precisamente, da relação entre dimensões sistêmicas e domésticas que são convencionalmente o foco, respectivamente, de certas teorias de política internacional e de certas abordagens de APE.

Também voltado a interpretar a prática estatal, porém a partir de um arcabouço conceitual bastante diferente, está o texto de Leonardo Ventura e Rafael Pedroso. Nos últimos anos, um dos lugares de maior inovação teórica no campo de RI vem da interação com a psicanálise, que já vem gerando excelentes trabalhos no Brasil (por exemplo, Selis, 2019; Sandrin, 2020). Ventura e Pedroso mobilizam a tríade sujeito-desejo-fantasia, de extração lacaniana, juntamente com os conceitos de biopolítica e necropolítica, para a interpretação da violência estatal nas Filipinas. Da leitura do texto, pode-se depreender como a interação entre Psicanálise e Relações Internacionais tem considerável potencialidade não apenas para os 
estudos em segurança internacional, mas também para teorizações sobre diversos outros aspectos da coexistência política.

A área de segurança internacional também é abordada por Miguel Borba de Sá. A partir de seu estudo sobre a Missão das Nações Unidas para Estabilização do Haiti (Minustah), o autor identifica, tanto em parte substancial do debate acadêmico no Brasil quanto em manifestações de autoridades estatais e organizações nãogovernamentais, uma "frequente postura favorável ao 'jeito brasileiro'” de atuar em operações de paz. Além disso, o texto afirma haver uma quase completa ausência no debate acadêmico brasileiro de uma teorização radical sobre intervenções humanitárias. Trazendo aportes teóricos gramsciano, foucaultiano, pós-colonial e feminista, o texto busca fomentar essa teorização, o que, segundo o autor, requer interrogar "o intervencionismo humanitário para além dos limites aos quais os paradigmas da Paz Híbrida ou da Paz Adaptativa tentam circunscrevê-lo".

O texto de Aureo Toledo interroga os fundamentos da categoria de "estado falido" tal como articulada nos documentos de política externa dos Estados Unidos durante o governo de George W. Bush (2001-2008). Toledo mostra como essa categorização está ancorada na perspectiva teórico-metodológica do "Novo Institucionalismo". Recorrendo a reflexões de expoentes dos estudos "pós-coloniais", o texto argumenta que essa perspectiva institucionalista, ao desconsiderar a dimensão internacional do problema diagnosticado e contribuir, dessa forma, para a legitimação de "intervenções reformistas" com o objetivo de modificar a situação política de "países considerados fracos", atualiza o "Discurso Colonial". Nas palavras de Toledo: "se a intervenção no Discurso Colonial era justificada pela tentativa de se educar os 'povos degenerados', no discurso sobre o fracasso estatal a intervenção seria explicada e incentivada com base na existência de 'instituições degeneradas'”. 4

A interpretação do marxismo como teoria das Relações Internacionais e a ênfase em seu aporte para a análise da atuação dos Estados Unidos na economia política capitalista são as duas principais contribuições do texto de Ana Garcia. A autora, com uma produção bibliográfica de extrema relevância para o debate marxista no campo (ver, por exemplo, Garcia, 2010; Bugiato, Garcia e Ramos, 2017; e Garcia e Bugiato, 2019), se dedica neste artigo a uma apresentação didática de

\footnotetext{
${ }^{4}$ Cabe notar que Aureo Toledo (por exemplo, Toledo e Facchini, 2017) e Miguel Borba de Sá (2019) vêm propiciando contribuições importantes nos últimos anos para o debate sobre os conceitos de "paz" nos estudos internacionais.
} 
linhas gerais dessa abordagem e de sua rearticulação posterior por Antonio Gramsci, Nicos Poulantzas, Robert Cox, Sam Gindin e Leo Panitch. Os três últimos são mobilizados por Garcia para uma discussão sobre a ideia de "internacionalização do estado" e sua importância para o entendimento do imperialismo e da hegemonia nas reconfigurações da economia política capitalista nas últimas décadas, assim como da atuação dos Estados Unidos nesse período.

A importância das teorias do imperialismo para a análise do engajamento dos Estados Unidos na política internacional ganha outro contorno por parte de Felipe Mendonça, Pedro Cicero e Marisa Amaral. Depois de uma revisão da contribuição das vertentes clássicas dessas teorias para a análise da política internacional, 0 artigo traz uma fundamental discussão sobre a relação entre imperialismo e racismo na inserção internacional do Estados Unidos e na discussão teórica predominante no país. A leitura do texto não poderia ser mais importante para quem se interessa por um caminho interpretativo que busque entender os elos e tensões entre a teorização acadêmica no campo de RI e as relações de poder no sistema internacional. A agenda de pesquisa delineada pelo texto ao final tem enorme potencialidade, podendo até mesmo abrir frestas para se entender como esses elos e tensões ressoam e são reconfigurados em outros lugares do mundo, inclusive no Brasil. ${ }^{5}$

A partir de cruzamentos de abordagens feministas e pós-coloniais, Nicole Minvielle chega a um "feminismo pós-colonial" que, atento à interseccionalidade de raça, gênero, classe e outros marcadores da discriminação, lança luz sobre a multidimensionalidade da violência na dinâmica de mulheres refugiadas no "Sul Global". Faz parte dessa dinâmica, como diz a autora, o modo como instrumentos internacionais (como convenções e declarações) mobilizados para lidar com o refúgio não são condizentes com a heterogeneidade das experiências das mulheres de várias partes do mundo que estão nessa condição. Destaca Minvielle, ainda, que o "Ocidente" constrói "uma identidade única da mulher muçulmana oprimida"; e que, nos campos de refugiados, "constrói-se a imagem da mulher 'subdesenvolvida', como vítima de sua própria cultura e que precisa ser resgatada de culturas bárbaras e subdesenvolvidas".

\footnotetext{
${ }^{5}$ Como se pode perceber, os textos de Aureo Toledo, de Ana Garcia e de Felipe Mendonça, Pedro Cicero e Marisa Amaral, se colocados em debate, também trazem interpretações distintas sobre o papel do Estados Unidos na política internacional nas últimas décadas.
} 
A construção homogeneizante ou "monolítica" de mulheres do Oriente Médio é igualmente problematizada por Jessica de Oliveira. Nesse caso, porém, isso é feito por meio de uma fascinante interação com a escritora e ativista feminista Fatema Mernissi. De acordo com Oliveira, Mernissi nos ajuda a "desmantelar macronarrativas orientalistas" sobre pessoas muçulmanas; "tornar tais indivíduos e sociedades visíveis através de referenciais menos violentos"; "destacar a zona de contato sempre viva entre culturas"; e "ilustrar como tradição e herança culturais, em vez de fixas no tempo e em territórios bem demarcados, podem ser compreendidas como a soma de memórias e fantasias persistentes que viajam através do tempo, do espaço e das mentes". A sofisticada interpretação que Oliveira nos oferece não para aí. Ela também mostra que a complexidade das questões que marcam as intervenções de Mernissi nos coloca sempre diante de possibilidades, mas também de limites no exercício crítico que caminha nas fronteiras, transgredindo-as, assim como as respeitando. 6

Se Felipe Mendonça, Pedro Cicero e Marisa Amaral avançam um questionamento fundamental sobre a relação entre racismo e teorização em Relações Internacionais, Nicole Minvielle e Jessica de Oliveira enfatizam outros marcadores de discriminação igualmente relevantes. Os próximos textos do Dossiê, por sua vez, nos conduzem a outros aspectos da produção teórica em RI no Brasil.

Jocieli Decol e Igor da Silva, ao fazerem um mapeamento dos programas de de doutorado em Relações Internacionais no Brasil, evidenciam uma considerável desigualdade regional. O foco do texto, no entanto, está na análise da teorização presente nas teses em RI produzidas na Pontifícia Universidade Católica do Rio de Janeiro (PUC-Rio) e em Estudos Estratégicos na Universidade Federal do Rio Grande do Sul (UFRGS). O estudo mostra que há pluralidade teórica nessas teses, mas que o diálogo com "teorias do Sul" ainda é minoritário, mesmo nos trabalhos que discutem "teorias pós-positivistas/reflexivistas".

A configuração acadêmica brasileira, especialmente a chamada "Escola de Brasília", recebe uma leitura por outro ângulo no texto de Luciano Muñoz e Raphael Spode. Ambos têm feito estudos no campo de RI interagindo criticamente com o pensamento da política externa brasileira (ver, por exemplo, Muñoz, 2016a, 2016b, 2019; e Spode, 2017). Nesse texto, por meio de um esforço comparativo da

\footnotetext{
${ }^{6}$ Estas e outras questões foram trabalhadas também em Oliveira (2019).
} 
produção acadêmica brasileira com a indiana no campo de RI, Munõz e Spode defendem a necessidade de aprofundamento do diálogo entre "construções teóricas contra-hegemônicas ocidentais - tais como as correntes do pós-positivismo em Relações Internacionais - e o conhecimento subalternizado do Sul Global". No que concerne ao Brasil, trata-se, para eles, de promover três movimentos (que o próprio artigo, vale notar, exercita de maneira muito produtiva): trazer ao campo de RI aportes de "autores brasileiros clássicos" de variadas áreas do conhecimento; colocar em contato, em "via de mão dupla" (grifo no original), esses aportes com teorias do campo; e "refletir acerca da problematização de dicotomias tais como centro/periferia, tradicional/moderno e interno/externo" (grifo no original). Tem-se aqui, sem dúvida, uma das mais promissoras agendas de pesquisa para a teorização em RI.

Ananda Oliveira se dedica à problematização da questão racial na produção de conhecimento na modernidade. Segundo ela, o "projeto de conhecimento científico da modernidade objetificou os corpos negros, negando sua capacidade de autoridade e de busca pelo saber, produzindo conhecimentos que não atendem aos interesses e demandas de povos negros, reduzindo seu ser a um corpo biológico, irracional, animalizado". O campo de RI, inclusive no Brasil, é parte desse projeto. Recorrendo a nomes centrais para o pensamento sobre relações raciais, em particular Abdias do Nascimento e Lélia Gonzalez, o artigo nos ajuda a entender alguns aspectos que marcam a produção de conhecimento em RI no país. A reprodução de estruturas racistas no pensamento no campo de RI não somente se liga a uma perda de diversidade de saberes, mas também "pode limitar a compreensão do internacional, assim como constranger as possibilidades de estudo de sujeitas e sujeitos negros".

As relações raciais na produção acadêmica de $\mathrm{RI}$ no Brasil também são abordadas por Blenda Santos de Jesus. Depois de interagir com parte da já considerável produção estrangeira sobre a questão racial na teorização em $\mathrm{RI}$, assim como com nomes fundamentais para essa discussão em outros campos de conhecimento, inclusive no Brasil, o artigo se dedica a refletir sobre o silenciamento ainda marcante no campo acerca "da contribuição e da representação do negro". A tarefa que o texto nos coloca é a seguinte: "pensar o espaço social e simbólico do negro", diz Jesus, "demanda uma mudança no conjunto de mecanismos teóricos e 
metodológicos das RI, e das ciências, de modo geral, e o esforço e dedicação dos pesquisadores que se propõem a investigar a internacionalização de conceitos e práticas raciais no Brasil, especialmente, a partir de autoras e autores negros".

Os textos de Ananda Oliveira e Blenda Santos de Jesus trazem reflexões tão urgentes quanto complexas sobre marcadores de discriminação racializados na atribuição daquilo que se considera como conhecimento legítimo na "modernidade" e, mais especificamente, no campo de RI. Essas reflexões nos incitam a repensar a reprodução do racismo na teorização de RI e mostram que a problematização do tema vem gerando agendas de pesquisa fascinantes e que nos possibilitam levar adiante modalidades antirracistas de pensamento e de (re)construção de mundos.

Se os quatro textos acima nos aproximam criticamente da produção teórica em RI no Brasil, os três próximos textos do Dossiê nos conduzem a uma problematização da relação entre a teorização em $\mathrm{RI}$ e os marcadores de discriminação constitutivos da modernidade.

O artigo de Gustavo Bezerra, Pedro Salgado e Roberto Yamato materializa um esforço sistemático de reflexão sobre a ordem política moderna (ver, por exemplo, Herz e Yamato, 2018; Yamato, 2019; Salgado, 2019). ${ }^{7}$ Por meio de uma interpretação crítica da Escola Inglesa, os autores argumentam que há um silenciamento do campo de RI sobre a escravização atlântica, que seria, para eles, uma "instituição fundamental" do que se concebe como "sociedade internacional". O diálogo que o texto conduz com a sociologia histórica e com estudos "pós-coloniais" e "decoloniais" não somente problematiza concepções largamente sedimentadas em certas teorizações das RI, como também a relação entre modernidade e escravização. A agenda de pesquisa aberta pelo texto pode fortalecer debates que atravessam diferentes campos de conhecimento e diversas configurações históricas, culturais, sociais, políticas.

Por outra via, também é a modernidade que é problematizada por Marta Fernández, que tem feito intervenções incontornáveis no debate pós-colonial e decolonial no campo de RI no Brasil nos últimos anos (ver, por exemplo, Fernández,

\footnotetext{
7 Gustavo Bezerra vem desenvolvendo importante pesquisa de doutorado sobre história do Atlântico e escravidão no século XIX, interagindo com discussões em história e teoria das Relações Internacionais.
} 
2014; e Fernández e Esteves, 2017).8 A autora discute a cumplicidade das Relações Internacionais com o "projeto colonial" e argumenta que os conceitos de "estado de natureza", "contrato social" e "estado moderno" - "os principais mitos e categorias" das Relações Internacionais - "participam do processo extremamente violento de desqualificação da diferença e de opressão das minorias étnico-raciais que operam fora da gramática da modernidade". Sendo constitutivo da modernidade, esse processo também marca as "disciplinas" a ela atreladas, incluindo as Relações Internacionais. Por isso, Fernández propõe uma interpretação que provincialize e racialize teorias como o "neorrealismo" e o "liberalismo". Dando um passo adiante, o artigo recorre à filosofia ubuntu como forma de reimaginação do mundo "a partir de outros mundos".

Onofre dos Santos Filho, um dos nomes mais importantes na construção do campo de RI no Brasil, conduz uma instigante e precisa releitura de pensadores canonizados na teoria política moderna, Thomas Hobbes e John Locke. Essa releitura busca entender a construção da "ordem político-espacial" através do modo como ela articula certas concepções de "estado de natureza", "anarquia" e "contrato social". Através dessa articulação, produz-se, conforme Santos Filho, uma "clivagem entre Norte e Sul" que "não mais diz respeito a fiéis e infiéis, mas se faz entre sociedades contratuais e não contratuais, entre aqueles civilizados e não civilizados". Ao consolidar a noção de "internacional" como algo similar ao "estado de natureza", em que predomina a "anarquia", a teorização das Relações Internacionais reifica a forma "moderna-ocidental" do estado e, ao fazê-lo, reifica "o próprio sistema de estados e o ordenamento desigual a que a sua expansão pela superfície terrestre também deu origem".

Além dos textos inéditos apresentados até aqui, o Dossiê também traz a tradução de um artigo de Cristina Rojas.9 Rojas identifica tensões entre, de um lado, "lógicas coloniais da modernidade capitalista" - e suas divisões natureza/cultura, modernos/não-modernos e avançados/atrasados - e, de outro, pensamentos que "fraturam a episteme e a ontologia modernas". Explorando a noção de "pluriverso" a

\footnotetext{
${ }^{8}$ Fernández também é editora, juntamente com D. Nabers, C. Pan e D. B. MacDonald, da série de livros Global Political Sociology, publicada pela Palgrave Macmillan. Ver: https://www.palgrave.com/gp/ series/15803. Último acesso em 25 de março de 2020.

9 A tradução foi possível pelo apoio que recebemos desde o início por parte de Rojas e, principalmente, pelo trabalho minucioso de Paulo Chamon, ele próprio alguém que propiciou recentemente uma valiosa reflexão sobre o conceito de "tempo" na teorização em RI (Chamon, 2018). A revisão técnica da tradução foi feita por João Nackle Urt.
} 
partir de perspectivas da "ontologia política", o artigo coloca nosso pensamento diante da existência de muitos mundos. A abertura ético-política a formas alternativas de ser e conhecer, entendidas como "diferença radical", perturba a familiaridade do mundo moderno e pode, com isso, fomentar projetos alternativos e coletivos de solidariedade.

Os textos de Marta Fernández, Onofre dos Santos Filho e Cristina Rojas instigam tanto pelos seus muitos pontos de contato, como também pela complexa discussão que podem gerar em uma leitura comparativa. Não sendo aqui o espaço para avançar nessa direção, queremos apenas destacar um aspecto, encaminhando-nos para a conclusão desta introdução. Fernández recupera a filosofia ubuntu como uma concepção "alternativa de mundo, antitética ao projeto moderno/colonial". Rojas, por sua vez, convoca a uma política pluriversal que perturbe e frature as lógicas da modernidade. Já Santos Filho afirma que, "mesmo que possamos produzir teorias genuinamente do Sul", não se pode deixar de lado que "integramos um sistema de pensamento que deve se abrir ao entendimento e reconhecimento de outros saberes, mas que não opera nos mesmos termos desses outros saberes". Assim sendo, segue Santos Filho, "[n]osso lugar de discurso é o da ciência ocidental e o que podemos fazer é subvertê-la no sentido de recorrer às suas categorias, mas lendo-as em um registro diferente daquele que convencionalmente é feito a partir do Norte. Em outras palavras, à maneira das etnias que aqui existiam quando dos Descobrimentos, empregá-las a serviço de regras, costumes ou convicções estranhas ao seu aparato interpretativo e às relações de poder que engendram e sustentam a estruturação desigual do sistema ou da sociedade internacional" (grifo no original). Fernandéz, Rojas e Santos Filho nos instigam a levar o pensamento ao limite, a operar no limite, explorando as possibilidades e impossibilidades da transgressão na relação com a alteridade, sem deixar que reconhecer o(s) lugar(es) de onde nós partimos. E quem seria este "nós"? E qual seria este lugar?

O Dossiê se encerra com uma entrevista feita com João Pontes Nogueira. Além de importante contribuição bibliográfica para a teorização em RI no Brasil (ver, por exemplo, Nogueira e Messari 2005; Huysmans e Nogueira, 2012, 2016; Nogueira, 2003), Nogueira participou de momentos fundantes na institucionalização do campo no país e vem fomentando há anos a discussão de perspectivas pós- 
estruturalistas, pós-coloniais, decoloniais, entre outras, no ensino e na pesquisa aqui desenvolvidos. A entrevista está dividida em duas partes: a primeira, de escopo mais amplo, aborda a relação do campo das Relações Internacionais com a universidade e o debate público; a segunda se foca na teorização em RI pensada a partir do Brasil. Entre os muitos pontos trazidos nas respostas, destacamos dois, antes de concluirmos a introdução - ou melhor, abrirmos o Dossiê.

Primeiro. Nogueira afirma: "se, de fato, os obstáculos estruturais à produção de teoria na periferia ainda perduram, é importante dizer que o contexto vem mudando gradualmente". Essa mudança pode ser percebida em vários locais: na participação de pesquisadoras(es) do "Sul" em eventos internacionais, na crescente publicação de textos em periódicos estrangeiros de ponta e na maior possibilidade de construção de redes transnacionais de pesquisa. Somando-se a isso, poderíamos mencionar o adensamento, ainda que subexplorado e sempre padecendo da falta de recursos, de redes formais e informais entre instituições e/ou pesquisadoras(es) brasileiras(os). Além disso, destacamos um segundo ponto. Nogueira identifica, como "uma das tendências mais encorajantes do campo hoje no Brasil", aquilo que chama de "impulso vigoroso no sentido da incorporação estudos teóricos de gênero e raça na produção acadêmica de RI". Ainda em suas palavras, "existe uma energia criativa entre os jovens pesquisadores de RI que promete coisas interessantes no campo teórico". Poderíamos dizer que este Dossiê parece indicar que essa energia criativa já é mais do que apenas uma promessa...

Em suma, esperamos que a diversidade temática e teórica dos textos do Dossiê, assim como do perfil acadêmico, da filiação institucional e da localização regional de dos nomes nele presentes, contribua para um fortalecimento da teorização em RI no Brasil que se combine com um intenso atravessamento de fronteiras pelos mais variados campos de conhecimento. Ademais, é um propósito do Dossiê incentivar que essa combinação seja explorada também através da intensificação da interação com o que é produzido no âmbito da teorização em RI no próprio país. Mais precisamente, trata-se de um duplo desafio. Por um lado, a problematização da divisão global do trabalho intelectual requer o reconhecimento e a contestação da reprodução de "centros" e "periferias" no próprio âmbito acadêmico brasileiro. Por outro lado, é crucial o aprofundamento de debates com a produção teórica no Brasil, sem prejuízo da contínua interação com o que é produzido em 
outros locais - nesse caso, preferencialmente com a diversificação desses locais, para além dos Estados Unidos, do Canadá e de um pequeno grupo países europeus.

Esse duplo desafio nos incita a responder a uma pergunta assim formulada por Onofre dos Santos Filho em seu artigo: "como pensar um mundo assim ordenado a partir do nosso lugar no mundo?". Para as múltiplas respostas possíveis, não resta dúvida de que a teorização em Relações Internacionais no Brasil importa. E que importe cada vez mais, cada vez melhor.

Por fim, mas não menos importante, cabe ressaltar a natureza coletiva da iniciativa que culminou com a realização deste Dossiê. Sua formulação teve início há pelo menos três anos e ganhou materialidade na proposta acolhida pela revista Monções, que aqui referimos na pessoa da equipe editorial - Bruno Bernardi, Déborah Monte e Matheus Hernandez. Mais de trinta trabalhos foram submetidos, o que demandou o esforço analítico de aproximadamente sessenta pareceristas, que buscamos entre professoras(es) e autoras(es) de Teoria das RI de universidades sediadas em todas as regiões do País, e que trabalharam voluntariamente num intenso processo de avaliação, edição e revisão. A todas essas pessoas, que tornaram possível esta publicação, agradecemos imensamente. 


\section{Referências}

BORBA DE SÁ, M. "Haitianismo": colonialidade e biopoder no discurso político brasileiro. Tese de doutorado em Relações Internacionais, Pontifícia Universidade Católica do Rio de Janeiro, 2019.

BUGIATO, Caio; GARCIA, Ana Saggioro; e RAMOS, Leonardo. Posfácio: marxismo e Relações Internacionais: um breve balanço. Estudos Internacionais, vol. 5, n. 3, p.126-134, 2017.

CHAMON, Paulo. Turning temporal: on discourse of time in IR. Millennium 46(3), 2018, p. 396-420.

COX, Robert W. Social Forces, States and World Orders: Beyond International Relations Theory. Millennium 10 (2), 1981, p. 126-155.

DIRLIK, Arif. The end of colonialism? The Colonial Modern in the Making of Global Modernity. Boundary 2, Duke University Press, v. 32, n. 1, 2005, p. 1-31.

E-MEC. Cadastro e-MEC: Cadastro Nacional de Cursos e Instituições de Educação Superior. Consulta Avançada. Disponível em: <https://emec.mec.gov.br/emec/ nova\#avancada>. Acesso em: 25/3/2020.

FERNÁNDEZ, Marta. O Cosmopolitismo Kantiano: Universalizando o Universalismo. Contexto Internacional, v.36 n.2, p. 417-456, 2014.

FERNÁNDEZ, Marta e ESTEVES, P. L. M. L. Silencing Colonialism: Foucault and the International. In: BONDITTI, Philippe; BIGO, Didier; GROS, Frédéric (orgs.). Foucault and the Modern International. Silences and Legacies for the Study of World Order. 1ed.Londres: Palgrave, 2017.

GARCIA, Ana Saggioro. Hegemonia e imperialismo: caracterizações da ordem mundial capitalista após a Segunda Guerra Mundial. Contexto Internacional, vol. 32, n.1, p.155-177, 2010.

GARCIA, Ana e BUGIATO, Caio. Repensando o estado o imperialismo nas Relações Internacionais: as contribuições teóricas De Leo Panitch. Revista de Estudos Internacionais (REI), vol. 10, n. 2, p.3-18, 2019.

HERZ, Mônica e YAMATO, Roberto Vilchez. As Transformações das Regras Internacionais sobre Violência na Ordem Mundial Contemporânea. DADOS Revista de Ciências Sociais, Rio de Janeiro, vol. 61, n. 1, p. 3 a 45, 2018.

HOOKS, Bell. Ensinando a transgredir: a Educação como prática de liberdade. Tradução de Marcelo Brandão Cipolla. São Paulo. 2013. Editora Martins Fontes, 2013. 
HUYSMANS, Jef e NOGUEIRA, João Pontes. International Political Sociology: opening spaces, stretching lines. International Political Sociology, vol. 6, n. 1, p. 1-3, 2012. 299-319, 2016.

Ten years of IPS: fracturing IR. International Political Sociology, vol. 10, p.

MUÑOZ, Luciano da Rosa. A renovação de credenciais no Brasil: indicações para uma análise à luz da governamentalidade. Monções: revista de Relações Internacionais da UFGD, vol. 6, n. 10, jul/dez, p.269-295, $2016 \mathrm{a}$.

. O conceito de autonomia em Puig e Jaguaribe: uma análise comparativa intertextual. Carta Internacional, v. 11, p. 200-221, 2016b.

. Intelectuais, militares, diplomatas: uma genealogia da autonomia no Brasil (1946-1974). Tese de doutorado apresentada no Instuto de Relações Internacionais da Universidade de Brasília, Brasília, 2019.

NOGUEIRA, João Pontes. Ética e violência na Teoria das Relações Internacionais: uma reflexão a partir do 11 de setembro. Contexto Internacional, vol. 25, n. 1 , jan./jun., p. 81-102, 2003.

NOGUEIRA, João Pontes e MESSARI, Nizar. Teoria das Relações Internacionais: correntes e debates. Rio de Janeiro: Elsevier, 2005.

OLIVEIRA, Jessica da Silva C. Postcolonial Maghreb and the Limits of IR. London: Palgrave Macmillan, 2019.

PLATAFORMA SUCUPIRA. Cursos avaliados e reconhecidos. Disponível em: $<$ https://sucupira.capes.gov.br/sucupira/public/consultas/coleta/programa/quantitativo s/quantitativoBuscaAvancada.xhtml>. Acesso em: 24/3/2020.

SALGADO, Pedro. Agency and geopolitics: Brazilian formal independence and the problem of Eurocentrism in international historical sociology. Cambridge Review of International Affairs, Publicado online em 22 de julho de 2019.

SANDRIN, Paula. Symptomatic enjoyment: a postcolonial and psychoanalytic interpretation of Turkey's relations with the European Union. Journal of International Relations and Development, Publicado Online em 22 fevereiro de 2020.

SELIS, Lara Martim Rodrigues. At the edge of language: rereading subalternity through misrecognition and sinthome. Tese de doutorado apresentada no Instituto de Relações Internacionais da Pontifícia Universidade Católica do Rio de Janeiro, Rio de Janeiro, 2019.

SPIVAK, Gayatri C. A Critique of Postcolonial Reason: Towards a History of the Vanishing Present. Harvard UP, 1999. 
. A conversation with Gayatri Chakravorty Spivak: politics and the imagination, interview by Jenny Sharpe, Signs: Journal of Women in Culture and Society, 28(2): 609-24, 2003.

SPODE, Raphael. An Inquiry into the Moral and Religious Dimensions of International Politics: the Thought and Contribution of Rui Barbosa. Contexto Internacional, vol. 39, n. 1, Jan/Abr, p. 53-73, 2017.

TICKNER, Arlene B.; BLANEY, David (eds.) Thinking International Relations Differently. London and New York: Routledge, 2012.

. Claiming the International. London and New York: Routledge, 2013.

TICKNER, Arlene B.; WAEVER, Ole (eds.) International Relations Scholarship Around the World. London and New York: Routledge, 2009.

TOLEDO, Aureo e FACCHINI, Julia. Da transformação de conflitos à paz híbrida: uma análise das ideias de Paul Lederach e Roger Mac Ginty. Revista Brasileira de Estudos de Defesa, vol. 4, n. 2, p.153-174, jul./dez., 2017

YAMATO, Roberto Vilchez. Beyond the line: Carl Schmitt and the constitutive outsider of the international. Politics, 39(2), 218-232, 2019. 